\title{
Interactive comment on "Application of FLaIR model for early warning system in Chibo Pashyor, Kalimpong, India for rainfall-induced landslides" by Abhirup Dikshit and Neelima Satyam
}

\section{Anonymous Referee \#1}

Received and published: 8 September 2017

Major revisions are requeted before publication, and I suggest to consider the manuscript as a technical paper and not as a research paper, because a well-known (in literature) model is applied for a selected case study.

In details: Introduction part is very poor in terms of references. Authors could consider many references presented in De Luca and Versace (2017), DOI 10.1007/s10346-0160768-5, or in Guzzetti et al (2007) - Rainfall thresholds for the initiation of landslides in Central and Southern Europe - Meteorology and Atmospheric Physics 98(3):239-267, in order to cite many examples or schemes like ID or with antecedent precipitation.

Printer-friendly version

Discussion paper

For the selected case study, it should be highlighted which is the advantage of using 
FLaIR model with respect to other most adopted models, like ID (in terms of number of True Positives, False Negatives, False Positives).

Page 10, Fig. 6: the linear transfer function is wrong. A transfer function is a filter, and its mathematical definition requires that the area of this function with the horizontal axis is equal to 1 (and this property is not respected in the figure). Consequently, also Figure $6 \mathrm{e}$ is wrong (the values on the vertical axis are unrealistic)

Page 12: for the mixture of exponential functions, parameters values are the same of Sirangelo and Braca (2004), used for Sarno (Italy). Did Authors calibrate the model for their study area, or they assume the same parameters of Sarno without calibration for their case study? (in this second case I do not agree with authors). Moreover, values of mobility function are very low for the adopted parameters set.

References section should be significantly adjusted.

Interactive comment on Nat. Hazards Earth Syst. Sci. Discuss., https://doi.org/10.5194/nhess2017-295, 2017.

Printer-friendly version

Discussion paper 